\title{
La música que des-cubre el silencio: Pedagogías decoloniales para la educación musical de personas sordas
}

\section{Artículo de investigación}

\section{Liliana Elizabeth Otero Caicedo}

Universidad de Nariño, Colombia

leoteroc@unal.edu.co

Recibido: 13 de febrero de 2020

Aprobado: 10 de junio de 2020

Cómo citar este artículo: Otero Caicedo, Liliana Elizabeth (2021). La música que des-cubre el silencio: Pedagogías decoloniales para la educación musical de personas sordas. Calle 14: revista de investigación en el campo del arte 16(29). pp. 118-127.

https://doi.org/10.14483/21450706.17407

Un profundo agradecimiento y reconocimiento a la comunidad sorda de Colombia, sin ella todas estas reflexiones no habrían sido posibles.

\section{(c) (1)}

https://creativecommons.org/licenses/by/4.0/deed.es 


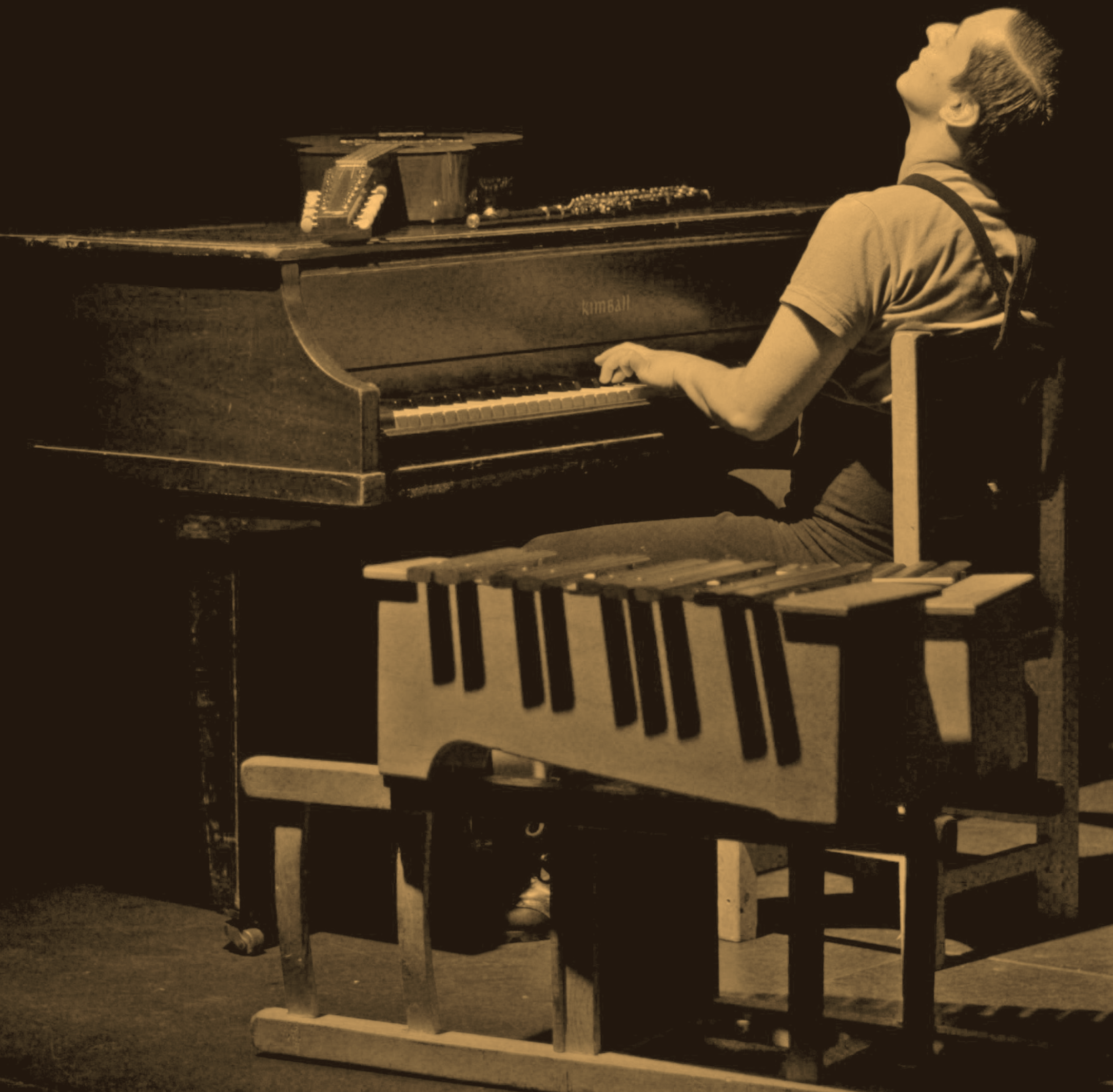




\begin{abstract}
Resumen
Hemos naturalizado la "limitación" de las personas sordas hasta tal punto que, desde la educación musical, son pocos los cuestionamientos para defender la música como un derecho humano fundamental. Más aún, los fundamentalismos binarios de deficiencia/capacidad, normal/ anormal, oyente/sordo, constituyen un horizonte colonial que somete a las personas sordas, anulando su ser-sonoro bajo los presupuestos dominantes de la ideología de la normalidad. Desde las pedagogías decoloniales, se comprende la experiencia musical como una práctica estética-política-pedagógica que debe provocar fracturas en el entendimiento hegemónico de este arte sonoro, posibilitando una descolonización del sonido que devenga en el reconocimiento del capital musical que tiene la comunidad sorda y, así, comprender la diferencia auditiva como la oportunidad de des-cubrir otros mundos musicales que legitimen las posibles destrezas innatas, las experiencias interculturales y los intereses en el campo musical de quienes habitan el silencio.
\end{abstract}

\title{
Palabras clave
}

Comunidad sorda; educación musical; música; pedagogías decoloniales

The music that uncovers silence. Decolonial pedagogies for the music education of deaf people

\begin{abstract}
We have naturalized the "limitation" of deaf people to such an extent that, from the music education field there are few offerings to defend music as a fundamental human right. Furthermore, the binary fundamentalisms of deficiency/capacity, normal/abnormal, hearing/ deaf, constitute a colonial horizon that overpowers deaf people, nullifying their 'sound being' under the dominant assumptions of the ideology of normality. From decolonial pedagogies, the musical experience is understood as an aesthetic-political-pedagogical practice that should cause fractures in the hegemonic understanding of this auditory art, enabling a decolonization of sound that accrues in the recognition of the musical capital that the deaf community has, and thus, understand the auditory difference as the opportunity to discover other musical worlds that legitimize the possible innate skills, the intercultural experiences and the interests in the musical field of those who inhabit silence.
\end{abstract}

\section{Keywords}

Deaf community; musical education; music; decolonial pedagogies

La musique qui découvre le silence. Pédagogies décoloniales pour l'éducation musicale des sourds

\section{Résumé}

Nous avons naturalisé la «limitation» des personnes sourdes à un tel point que, dans le domaine de l'éducation musicale, il y a peu d'offres pour défendre la musique comme un droit humain fondamental. En outre, les fondamentalismes binaires déficience / capacité, normal / anormal, auditeur / sourd, constituent un horizon colonial qui domine les sourds, annulant leur « être sonore » sous les hypothèses dominantes de l'idéologie de la normalité. A partir des pédagogies décoloniales, lsexpérience musicale est comprise comme une pratique esthético-politiquepédagogique qui devrait provoquer des fractures dans la compréhension hégémonique de cet art auditif, permettant une décolonisation du son qui s'accumule dans la reconnaissance du capital musical que possède la communauté sourde, et ainsi comprendre la différence auditive comme l'opportunité de découvrir d'autres mondes musicaux qui légitiment les compétences innées possibles, les expériences interculturelles et les intérêts dans le champ musical de ceux qui habitent le silence. 


\section{Mots clés}

Communauté sourde ; éducation musicale ; musique ; pédagogies décoloniales

A música que des-cobre o silêncio. Pedagogias decoloniais para a educação musical de pessoas surdas

\section{Resumo}

Temos naturalizado a "limitação" das pessoas surdas até o ponto em que, a partir da educação musical, são poucos os questionamentos para defender a música como um direito humano fundamental. Ainda mais, os fundamentalismos binários de deficiência/capacidade, normal/ anormal, ouvinte/surdo, constituem um horizonte colonial que submete as pessoas surdas, anulando seu ser-sonoro sob os pressupostos dominantes da ideologia da normalidade. A partir das pedagogias decoloniais, se compreende a experiência musical como uma prática estéticapolítica-pedagógica que deve provocar fraturas no entendimento hegemônico desta arte sonora, possibilitando uma descolonização do som que resulte no reconhecimento do capital musical que tem a comunidade surda e, assim, compreender a diferença auditiva como a oportunidade de des-cobrir outros mundos musicais que legitimem as possíveis destrezas inatas, as experiências interculturais e os interesses no campo musical daqueles que habitam o silêncio.

\section{Palavras chave}

Comunidade surda; educação musical; música; pedagogias decoloniais

\section{Tutai pakaskata upallaskata llugsichiku iachachiku sug runakunata mana Ullaskuakunata}

\section{Maillallachiska}

Mana kauanchi sugkunata nukanchimandalla,iuianchi chimanda kaipi munaku parlanga. Mana ullaslakunamanda paikunapas nukanchi sina llatata pudinkuna, achka katichiikuna ruranga paikuna iachaikuska tutai rurangapa suura llakispa mana ullangapa pudispa chimanda kunaura paikunamadapas tiami llapa suma aidachidurkuna mana sapalla sakingapa.

\section{Rimangapa ministidukuna}

Mana ullagkuna; tunaita iachaikugkuna; tunai; ñugpamanda iachaikuii 
La compresión de la música (...) podría formar seres humanos más aptos para escuchar y entender varios puntos de vista al mismo tiempo, más capaces de valorar cuál es su lugar en la sociedad y en la historia, seres

humanos con más posibilidades de captar las similitudes entre todas las personas que las diferencias que los

separan.

(Daniel Barenboim, 2008; énfasis propio)

La mirada que la sociedad les da a las personas con dis_capacidad ${ }^{1}$ es lejana y distorsionada. Estas miradas que se dirigen a la diferencia se configuran en términos de miedos vinculados a una imagen intolerable de la humanidad. Este miedo deviene en silencio, evitación y exclusión, ya que la falta o deficiencia se considera una desgracia que imprime, de forma incansable en la persona con dis_capacidad, una frustración de reconocimiento intersubjetivo (Pié, 2009). Es así como, "las personas con dis_capacidad han sido receptoras de una variedad de respuestas ofensivas por parte de las otras personas, entre ellas el horror, el miedo, la ansiedad, hostilidad, la desconfianza, la lástima, la protección exagerada y el paternalismo" (Barton. 1998, p.24). Tener una dis_capacidad supone experimentar la discriminación, la vulnerabilidad y los asaltos abusivos a la propia identidad y estima. Implica aislamiento y restricciones sociales. En las sociedades modernas, es una causa importante de diferenciación social, de manera que tanto para las personas con dis_capacidad como para las que no la tienen, tener una dis_capacidad es tener un problema, tener una dis_capacidad es "tener en ti algo que no es correcto" y que requiere ser corregido.

Sin embargo, las personas con dis_capacidad han luchado por proponer definiciones y apreciaciones diferentes respecto a la cuestión de la dis_capacidad, y, por ende, su lucha "es una lucha por la equidad, la justicia social, la ciudadanía y la legislación contra la discriminación" (Barton. 2009, p. 123). Desde esta perspectiva, la dis_capacidad: no se considera ya una tragedia, un castigo, el resultado de cierto(s) pecado(s) parental(es) o el pecado del mismo individuo; no es una enfermedad que requiere tratamiento; no debe ser el objeto de caridad, ni de acciones sentimentales y condescendientes que sólo crean dependencias. Es una cuestión de derechos humanos (Barton. 2009). De manera que, el problema no consiste en la persona con dis_capacidad;

$1 \quad$ Se utiliza el guion bajo para separar el prefijo dis. Seguiré utilizando esta escritura, pues este es un símbolo que más que separación significa ruptura lo que precisamente buscamos develar en el arte como un hacer ético, una ruptura entre el prefijo dis (anulación) y la palabra capacidad el problema es la forma en que se construye y quiénes construyen la noción de normalidad. Este es un término que es parte de la idea de progreso, la industrialización y la consolidación de la ideología del poder de la burguesía. Las implicaciones de la hegemonía de la normalidad son profundas y se extienden hasta el núcleo mismo de la producción cultural (Davis, 2009).

Con esto, es posible notar que la separación de lo normal y lo anormal está atravesada por relaciones de poder, pues el verdadero sustento de la normalidad son los valores definidos como preferenciales para el orden social en el que se inscriben. Los grupos sociales poderosos pretenden imponer sus propios valores, expectativas y creencias a toda la sociedad. Sus intereses se codifican en normas que esos grupos aspiran a que alcancen una aceptación más general, y en última instancia, universal. En consecuencia, el concepto de normalidad representa un reconocimiento de los valores que han terminado por imponerse para la reproducción del orden establecido, sin advertir que en el mismo momento en que se instalan valores preferenciales se excluyen otros, lo que implica también la exclusión de las personas que no son capaces de portar esos valores (Drake, 1998; Kiplen y Vallejos, 2009).

Esta imposición de quién es normal y quién es anormal, es la que fundamenta la colonización dentro del campo de la dis_capacidad. Podríamos decir que son las personas sin dis_capacidad, es decir, aquellas definidas como normales, las que se convierten en las colonizadoras de las personas con dis_capacidad, anteponiendo sus ideales de completud, perfección, belleza, eficiencia, capacidad, progreso y, en general, su humanidad, sobre las humanidades otras, aquellas que, como lo menciona Pié (2009), revelan como un espejo, la propia imperfección y debilidad que nos confronta con los límites de lo humano y con el riesgo a la propia disolución de la normalidad.

De manera que es el otro sin dis_capacidad quien impone los valores y haceres superiores que deben reproducirse dentro del orden establecido. Particularmente, en el caso de las personas sordas, somos los oyentes quienes se convierten en esos colonizadores que buscan instaurar las propias concepciones del mundo desde el sonido y negar aquellas humanidades que comprenden el mundo desde el silencio. Esto se evidencia en que, en diferentes contextos como el familiar, educativo, político, cultural etc., se presentan profundas dificultades y grandes desafíos en la convivencia de dos modalidades lingüísticas diferentes que están inmersas en un entramado 
de significados relacionales ambiguos, y que, por esta razón, vivirán dificultades en la comunicación. Por ejemplo, para algunas familias oyentes con un integrante sordo, la sordera es reducida a una dificultad para percibir sonidos, lo que subsecuentemente genera una dificultad para hablar, por tanto, se encaminan todos los esfuerzos a reparar la pérdida auditiva con la esperanza de que así la familia vuelva a la normalidad. Incluso, no podemos olvidar el sometimiento cultural que implica privilegiar la lengua oral sobre la lengua de señas, pues se considera a la primera como la lengua prestigiosa y única, por lo tanto, se ejerce una presión sobre la persona sorda para que se ajuste a la lengua de la mayoría y subyugar entonces su lengua de señas a un segundo plano lingüístico, cognitivo y emocional, lo que sin duda puede conllevar a una deprivación en donde prevalece la restricción de experiencias significativas y la construcción de una relación rígida y estereotipada con la persona sorda (Rubinowicz, 2009).

Esto, sin duda, muestra la colonización del oyente sobre el sordo en el marco de la ideología de la normalidad. Así pues, siguiendo a Walsh (2013), podríamos inferir que los agentes coloniales, por lo general, imponen y moldean una racionalidad binaria, en este caso oyente/ sordo, desde la cual la dis_capacidad se convierte en un instrumento de clasificación jerárquica y de patrones de poder. En otras palabras, el fundamentalismo binario de deficiencia/capacidad y normal/anormal, constituye un horizonte colonial que somete al poder imperante a las minorías relegando o anulando su ser bajo los presupuestos jerárquicos dominantes. Esta clasificación excluye la posibilidad de participación en todas las esferas de la sociedad y caracteriza con elementos deshumanizantes al ser de cada una de las personas sordas.

El aire vibrante golpeó las membranas del tímpano de Lord Edward; el sincronizado martillo, el yunque y el estribo se pusieron en movimiento hasta sacudir la membrana de la ventana oval y producir una historia infinitesimal en el fluido del laberinto. Las terminaciones vellosas del nervio auditivo se agitaron como olas en un mar alborotado; un gran número de oscuros milagros se produjeron en el cerebro, y Lord Edward susurro extasiado "iBach!". Sonrió con placer, le brillaron los ojos. (Aldous Huxley, citado en Swanwick, 2000; énfasis propio).

Por supuesto, una de las esferas de la sociedad en la cual las personas sordas son excluidas de manera naturalizada, es la esfera musical. Como lo muestra el epígrafe anterior, la música, ha sido hegemónicamente entendida como un fenómeno acústico, íntimamente relacionado con los componentes estructurales del sistema auditivo y sin los cuales resulta impensable que se pueda percibir. Además, pareciera ser que el cuerpo queda separado en la experiencia musical, favoreciendo la razón y la percepción intelectual, mientras que, en consecuencia, se reprueban las reacciones viscerales y otros estados emocionales afines (Regelsky, 2009). Más aún, olvidamos que, según lo señala Maldonado (2008) basado en los planteamientos de Deleuze, es el cuerpo el lugar donde acontece la música porque es él quien la vive; por lo tanto, cuando la música se reduce al sonido, la única parte del cuerpo que parece ser afectada es el oído; sin embargo, no se puede pensar que el oído es una especie de puente que conecta al individuo con la música. Es todo el cuerpo lo que es musicalizado.

Dentro de este contexto, la pregunta por el mundo musical de las personas sordas parece contradictoria, ya que la respuesta más obvia enunciaría que esta minoría no tienen cabida en el mundo musical simplemente porque presenta una limitación para escuchar. Dado esto, no es de extrañarse que el contemplar la posibilidad de que las personas sordas puedan experimentar y construir significados alrededor de este arte sonoro resulte paradójico, pues si la música es el sonido que se escucha con el oído, quien no pueda escucharlo, no puede comprender lo que la música es. Sin embargo, queda suspendidos varios interrogantes ¿a las personas sordas les interesa la música? ¿las y los estudiantes sordos actualmente reciben clases de música? Si no es así ¿por qué no participan de estas clases? ¿Qué pensaría si un docente de música tuviera que impartir sus clases a estudiantes sordos? ¿Acaso las personas sordas consideran relevante recibir educación musical? ¿Qué pasaría si lo hicieran? ¿Qué significa que no la reciban? ¿Qué han pensado las instituciones educativas al respecto? ¿Qué hemos reflexionado las comunidades académicas al respecto?

No podemos ignorar el hecho de que las personas sordas han sido segregadas del conocimiento y experiencia musical por considerar sus diferencias auditivas como barreras y no como oportunidades de redescubrir la música. Lo anterior tiene grandes implicaciones en la perpetuación de actitudes de segregación frente a poblaciones que no encajan en los parámetros de normalidad. El hecho de que las personas sordas no accedan a experiencias musicales se convierte en un acto que legitima la diferencia como una carencia, un problema o una falta de capacidad (discapacidad). Si nos adentramos en este cuestionamiento, entenderíamos 
que las personas sordas se están comprendiendo desde la limitación, dificultad, deficiencia, falta o anormalidad, por lo tanto, parecería un problema de la persona sorda lo que no le permite hacer parte del mundo musical, y no de las condiciones injustas de los entornos sociales, educativos y musicales. Como lo expresa Nussbaum (2007), la sociedad debe ofrecer las condiciones necesarias para que ciertas capacidades puedan desarrollarse en escenarios de elección, es decir, que se ofrezcan las adaptaciones para que estas personas elijan o no participar en el disfrute de la experiencia musical, enfatizando en que lo importante es que se confiera esta opción. Así, las personas sordas, no tendrían que adaptar sus preferencias, como consecuencia de un contexto con condiciones injustas, a lo que la comunidad oyente piensa que pueden alcanzar y a lo que la sociedad les dice que es una meta adecuada.

No obstante, hemos dado tan por sentado la barrera que tienen las personas sordas para escuchar que nos olvidamos que desde la educación musical son pocos los interrogantes y esfuerzos que se plantean para defender la música como un derecho humano fundamental y la experiencia musical como un conocimiento al que deben tener acceso todas las personas. Esto nos lleva a pensar que, desde paradigmas coloniales de la escucha, se han negado existencias musicales otras y se han dejado de reconocer las potencialidades para experimentar la música de diferentes maneras; es decir, se ha dejado de lado la exploración de un mundo musical desde el silencio. Podemos entonces suponer que está latente una colonización del sonido por parte de los y las oyentes la cual enraíza la exclusión musical de las personas sordas.

Investigaciones como las de Yennari (2010) y Hopyan, Gordon y Papsin (2011) son una pequeña muestra de que varios estudios que se realizan en torno a la música y a las personas sordas usualmente hacen comparaciones entre personas oyentes con audición normal y personas sordas, en las que obviamente se afirma que estas últimas perciben la música de una manera inferior a la de los oyentes. Lo que se objeta al respecto es ipor qué se espera que las personas sordas escuchen igual que los oyentes?, ¿acaso solo existe una manera de escuchar y sentir la música? ¿Por qué es necesario comparar la experiencia musical de una persona sorda con la de una persona oyente y querer normalizarla? ¿Se puede decir que hay una manera buena/mala, normal/anormal, erudita/ignorante de experimentar la música?

Al respecto, es necesario señalar que la música es esencial en la vida de una persona y de una sociedad, por lo tanto, el acceso a las experiencias musicales se constituye en un derecho humano fundamental y en un deber de la ciudadanía promoverlo (Lubet, 2009). De manera que el estudio crítico de la música en un contexto social provee una lección acerca de los derechos humanos en general y de los derechos de las personas con dis_capacidad en particular. A esto se debe agregar que, siguiendo los planteamientos de Gadamer, para Belén (2013) la obra de arte es concebida como un conocimiento que permite interpretar, organizar y reorganizar nuestra experiencia del mundo, un conocimiento al que no tienen acceso las personas sordas. Sin embargo, el valor cognoscitivo del arte no tiene que ver con la aprehensión de un objeto sino con su verdad, una verdad que nos permite reconocernos para profundizar nuestro conocimiento del mundo y de nosotros mismos. Lo que realmente se experimenta en una obra de arte, y así en la música, es hasta qué punto uno conoce y reconoce algo ella y, en este algo, a sí mismo, alcanzando un conocimiento que nos confronta, transformándonos y enriqueciendo nuestra experiencia del mundo.

Por todo esto, la educación musical está llamada a descubrir diversas aproximaciones a la música, igualmente válidas y dignificantes, en las cuales la audición no sea un prerrequisito para que las personas puedan encontrar en este arte sonoro una posibilidad de reconocerse a sí mismas y a sus pares en la diferencia, de construir escenarios de interacción en donde se compartan formas de ser y de estar en el mundo, de experimentar sensaciones y sentimientos que las interpelan y de empezar a gestar un cambio de paradigmas de exclusión desde la cultura. Sin embargo, no podemos olvidar que "la educación puede ocultar la realidad de la dominación y la alienación o puede, por el contrario, denunciarlas, anunciar otros caminos, convirtiéndose así en una herramienta emancipadora" (Freire. 2003, p. 74). En este caso, la educación artística, y en especial la educación musical, estaría ocultando bajo un velo sutil una realidad de dominación desde la visión del oyente que no cuestiona el acontecer musical de las personas sordas en el orden socialmente establecido. Esto sin duda, lleva a anular sensibilidades musicales otras, sentires musicales otros, aprendizajes musicales otros.

De manera que, la educación musical para la población sorda debe convertirse en una práctica política que provoque cuestionamientos y fracturas en las concepciones hegemónicas de la música, pero también que posibilite una descolonización del sonido. Es decir, reconocer el capital musical que tiene dicha población y valorar la diferencia auditiva como la oportunidad de 
descubrir otros mundos musicales desde la percepción, expresión, interpretación y disfrute particulares de la experiencia sonora, que legitimen las posibles destrezas innatas, las experiencias socioculturales e interese en el campo musical a quienes habitan el silencio. Se trata entonces, de proponer una praxis político-pedagógica desde la educación musical que ofrezca posibilidades para la valoración social de las diferencias en un camino que se orienta hacia la justicia, la dignidad, la libertad y la humanización posibilitando, en palabras de Walsh (2013) prácticas pedagógicas insurgentes hacia otro vivir, desafiando el poder hegemónico/colonial, animándose a pensar desde y con genealogías, racionalidades, conocimientos, prácticas y sistemas civilizatorios y de vivir distintos, para incitar posibilidades de estar, ser, sentir, existir, hacer, pensar, mirar, escuchar y saber de otro modo.

Dicho de otra manera, no se trata de desarrollar una pedagogía musical solo para la transmisión de un conocimiento sensible, sino para poner en escena la exclusión, opresión y deshumanización que implica la colonización del sonido para las personas sordas. Es develar todo el poder hegemónico imperante de la comunidad oyente que por muchos años ha sometido a la comunidad sorda, y es la educación musical la que debe dar respuesta y desnaturalizar la idea de que las personas sordas no tiene cabida en un mundo sonoro, pues no es la deficiencia si no la posibilidad de otras formas de experimentación musical las que deben contemplarse desde las pedagogías liberadoras. Por lo tanto, esta pedagogía musical tendría que escapar a los cánones que encierran la música, para disponerse a trasgredir, desplazar y tener incidencia en la negación existencial que se les ha impuesto a las personas sordas en la experiencia musical, la cual ha avasallado su sensibilidad, humanidad y conocimiento a lógicas hegemónicas y occidentales que imponen el deber ser de la educación musical. Estas serían pedagogías para leer críticamente el mundo e intervenir en la reinvención de una sociedad más humana que reconozca y valore la diferencia. De modo que estas pedagogías se erigen en las historias de las comunidades excluidas desde sus combates y persistencias, y son parte integral de sus luchas de concientización, desalienación y afirmación de su ser y hacerse humano. Siendo así, en este caso en particular la experiencia musical se convertiría en esa herramienta pedagógica que evidencia la lucha de la comunidad sorda por un acontecer descolonial que a su vez pueda promoverse pedagógicamente. La música se convertiría en esa práctica que permitiría rescatar los cuerpos sensibles, una humanidad vibrante y una existencia desde el silencio, para ejercer acciones artísticas-pedagógicas "insurgentes que den cuenta de cómo rebelar, resistir, agenciar, luchar y vivir pese a la colonialidad desde las fronteras y la subversión de la misma colonialidad" (Walsh. 2013, p. 36).

Ahora bien, es necesario señalar que no se tratar de colonizar a las personas sordas desde la música, ni que la vivan como los oyentes, por el contrario, se busca rescatar y valorar sus propias praxis musicales, entendida praxis como un "hacer tangible que marca una diferencia de algún tipo para el individuo o los grupos a los que se atiende" (Regelsky. 2009, p. 34). Desde la perspectiva de la praxis, el carácter casi sagrado de la obra musical se desmitifica y su significado pierde la supuesta naturaleza atemporal, anónima e independiente del lugar en que se dé. Las personas "escuchan" de acuerdo con las diferencias de sus mundos, valores, historias, necesidades e intenciones actuales. La actividad de escuchar se convierte en una práctica por derecho propio, con sus propias condiciones, criterio, fines y beneficios, por lo que se puede practicar en sus propios términos, en este caso en cuestión, desde los términos, intereses y potencialidades de la comunidad sorda.

Para esto, es necesario propender por una reflexión desde la comunidad sobre las implicaciones políticas, sociales y culturales en relación a su ausencia del mundo musical, con el fin de llegar a una concientización individual y colectica sobre el significado colonial de su segregación, pues la misma comunidad sorda, considera obvia y esperable su exclusión del mundo musical, encarnando una opresión y dominación que se internaliza tanto por la comunidad como por las instituciones artísticas e instancias educativas. Dado que, retomando el pensamiento de Freire (2005), es el oprimido el que no ve la opresión o el que busca quedarse en ese lugar de enunciación. Son ellas y ellos mismos, la comunidad sorda, quienes le dan la bienvenida al opresor, al desvincularse de experiencias musicales. En definitiva, la música vendría a ser el camino a través del cual se busca generar en la comunidad sorda esa concientización de dominación y opresión y agenciar unas luchas desde el hacer artístico que subviertan y transformen esa visión opresora-colonial.

Al respecto, debemos recordar como lo expresa Walsh (2013), citando a Fanon, que la descolonización implica no solo la toma de conciencia por parte de los oprimidos de su enajenación, sino la de los opresores en relación a su complicidad. En este caso, desde el campo educativo musical, las personas oyentes deben tomar 
conciencia de su complicidad en esta segregación, pues se ha contemplado esta ausencia del mundo musical como algo irrebatible, pues la decolonización requiere tanto del propio pueblo oprimido en este caso la comunidad sorda y que sean conscientes de su enajenación, como también del colonizador oyente y concientización de la complicidad en esa opresión sonora.

Es por esto que debemos propender por una pedagogía musical liberadora que haga de la opresión oyente y sus causas dentro de la experiencia musical, los objetos de reflexión de la comunidad sorda y el sector educativo, y desde esa reflexión generar un compromiso de lucha por su reconocimiento y liberación sonora. La invitación es la creación de otros mundos posibles, la creación de otras relaciones, y de otras humanidades, la posibilidad de desentrañar otras sensibilidades musicales, intersticios otros donde acaricia el sonido y donde el silencio es el paisaje en el cual cobra sentido una nueva existencia musical. Este es un llamado a que "cese para siempre el sometimiento del hombre por el hombre. Es decir, de mí por otro. Que se me permita descubrir y querer al hombre, allí donde se encuentre" (Fanon. 2009, p. 190).

Es así como el arte, y para estos efectos la música, se constituye en un camino privilegiado para pensar lo descolonial pedagógicamente, ya que permite la experiencia heterónoma, no homogeneizante del orden y provoca un movimiento hacia el otro-otra que implica una búsqueda mutua que escapa a la pretensión de integrar o incluir, para dejar simplemente ser. El arte, desde la simbolización del espacio (las artes plásticas: arquitectura, pintura y escultura), la simbolización del tiempo (música, danza) y la simbolización lingüística (poesía, literatura) nos inserta a una recepción paulatina pero efectiva de nuevas realidades. Así, el arte puede introducir una "simbolización restauradora y potencial de la experiencia política fundamental: de la anulación de la perversión técnica y el establecimiento de nuevos sentidos del mundo de la vida, de la reconstrucción de la naturalidad de lo humano" (Davis. 2009, p. 230). De ahí que el arte favorece:

conquistar la alteridad intima que implica la reapropiación de una verdad inalienable es apalabrar lo otro-otra, creando y recreando en la dimensión lingüística, espacial y temporal los nuevos significantes que permitan intentar escuchar el concierto de los sonidos del silencio, de la palabra enunciada y revivida en el potencial del espacio y tiempo, y que nos permite trasladar las significaciones de ceguera, sordera y parálisis de experiencias, de pensamientos a su dimensión originaria de lo social y cultural, y desde ahí iniciar la trasformación y creación de nuevas experiencias que nos depara revertir el destino funesto de la dis_capacidad hacia un nuevo destino de lo humano (Davis. 2009, p. 230).

Tomando en cuenta lo anterior, las personas sordas nos brindan otras comprensiones de la música y nos invitan a experimentarla desde lugares no registrados de nuestro cuerpo, desde otras latitudes sensitivas y desde otras estéticas sonoras para des-cubrir aquellos mundos sonoros que se ocultan entre el silencio. Esto permite ampliar la visión de la educación musical y contemplar otras praxis musicales que cuestionan las hegemónicas/coloniales/normalizadoras para expandir los alcances educativos de este arte sonoro. Por lo que no se trata desde la educación musical de seguir reproduciendo el bagaje simbólico de las culturas dominantes, sino de reconocer las experiencias musicales situadas en comunidades minoritarias para ir desaprendiendo estereotipos y cambiando las acciones opresoras y los sentires deshumanizantes acerca de las diferentes formas ser y estar en el mundo. Esta es invitación al campo de la educación artística y en especial de la educación musical, para componer a través de una lectura reflexiva, una polifonía que exprese los sentires intersubjetivos que legitimen la diferencia, para permitir que surjan espacios desde los cuales desentrañar nuevos significados, relaciones y creaciones para que las vivencias musicales puedan trasformar y/o subvertir o ser transformadas y/o subvertidas por otras subjetividades y colectividades para des-atar el cambio en pro de la existencia humanizada de otros mundos posibles.

\section{Referencias}

American Psychologycal Association (2010). Manual de Publicaciones de la American Psychological Association (6 ed.). México, D.F.: Editorial El Manual Moderno

Barenboim, Daniel. (2008). El sonido es vida. El poder de la música. Barcelona: Belacqua

Barton, L. (1998). Sociología y discapacidad. Algunos temas nuevos. En: L. Barton (Comp.), Discapacidad y Sociedad (pp. 19-33). Madrid, España: Morata.

(2009). La posición de las personas con discapacidad. En: P, Brogna. (Comp.), Visiones y revisiones de la discapacidad (pp. 123-136). México: Fondo de Cultura Económica. 
Belén, P. (2013). La obra de arte como lugar de verdad y conocimiento en la hermenéutica gadameriana.

En: D, Sánchez (Coord), Epistemología de las

Artes. La transformación del proceso artístico en el mundo contemporáneo (pp. 120-135). Editorial de la Universidad de La Plata.

Chen-Hafteck, L., y Schraer-Joiner, L. (2011). The engagement in musical activities of young children with varied hearing abilities. Music Education Research, 13

(1), 93-106. doi: 10.1080/14613808.2011.553279

Davis, L. (2009). Cómo se construye la normalidad. La Curva de Bell, la novela y la invención del cuerpo discapacitado en el siglo XIX. En P. En: P, Brogna. (Comp.), Visiones y revisiones de la discapacidad (pp. 188). México: Fondo de Cultura Económica.

Drake, R. (1998). Una crítica del papel de las organizaciones benéficas tradicionales. En: L. Barton (Comp.), Discapacidad y Sociedad (pp. 161-180).

Madrid, España: Morata.

Fanon, F. (2009). Piel negra, máscaras blancas. Madrid: Akal cuestiones de antagonismo

Freire, P. (2005). Pedagogía del Oprimido. México: Siglo XXI editores

(2003). El grito manso. Buenos Aires: Siglo

XXI editores

Hopyan, T., Gordon, K. A., y Papsin, B. C. (2011). Identifying emotions in music through electrical hearing in deaf children using cochlear implants. Cochlear Implants International, 12 (1), 21-26. doi: 10.1 179/146701010X12677899497399

Kipen, E., y Vallejos, I. (2009). La producción de la discapacidad en clave de ideología. En: A. Rosato y M. Angelino (coord.), Discapacidad e ideología de la normalidad. Desnaturalizar el déficit (pp. 155-175).

Buenos Aires, Argentina: Noveduc.
Lubet, A. (2009a). Disability, music education and the epistemology of interdisciplinarity. International Journal of Qualitative Studies in Education, 22 (1), 119-132. doi: 10.1080/09518390802581935

Maldonado, J. (2008). Música y creación: un sentido en el pensamiento de Gilles Deleuze. (Tesis de Doctorado). Universidad Autónoma de Madrid, Madrid, España.

Nussbaum, M. (2007). Las fronteras de la justicia. Consideraciones sobre la exclusión. Barcelona: Paidós.

Pié, A. (2009). Imágenes de la dis_capacidad.

Educación Social. Revista de intervención socioeducativa, 42, 93-103.

Regelski, A. (2009). La música y la educación musical: Teoría y práctica para marcar una diferencia. En: LINES, D.K. (coord.), La educación musical para el nuevo milenio (pp. 21-47) Madrid, España: Morata.

Rubinowicz, G. (2008). Conversaciones psicoterapéuticas con personas sordas: el uso de la lengua de señas para el diseño de entrevistas eficaces: Argentina, Buenos Aires: LibrosEnRed.

Swanwick, K. (2000). Música, Pensamiento y Educación. Madrid: Ediciones Morata.

Walsh, C. (2013). Lo pedagógico y lo decolonial. Entretejiendo caminos. Pedagogías Decoloniales. En: C. Walsh (Ed), Practicas insurgentes de resistir (re)existir y (re)vivir. Walsh C. Tomo I. Serie Pensamiento Decolonial (pp. 23-68). Ecuador: Quito: Abya Yala

Yennari, M. (2010). Beginnings of song in Young deaf children using cochlear implants: the song they move, the song they feel, the song they share. Music Education Research, 12 (3), 281-297. doi.org/10.1179/14 $6701010 \times 12677899497399$ 